\title{
Riscos de infecção cruzada frente a pandemia do COVID-19 em âmbito odontológico: o que há de mais recente na literatura?
}

\author{
Risks of cross-infection in the face of the COVID-19 pandemic in dentistry: what is the
} most recent in the literature?

Riesgos de infección cruzada frente a la pandemia de COVID-19 en odontología: ¿cuál es el más reciente en la literatura?

Lucas Menezes dos Anjos ${ }^{1 *}$, Aurélio de Oliveira Rocha², Rafaela de Menezes dos Anjos Santos ${ }^{1}$, Marcos Antônio Lima dos Santos ${ }^{1}$, Nailson Silva Meneses Júnior ${ }^{1}$, Thaine Oliveira Lima ${ }^{2}$, Priscilla Castro Moura Rodrigues².

\section{RESUMO}

Objetivo: Realizar um apanhado na literatura das informações mais recentes acerca do risco de infecção cruzada durante atendimento odontológico, bem como abordar cuidados de prevenção da contaminação por COVID-19. Métodos: Revisão Sistematizada da Literatura. Foi realizada uma busca completa por estudos recentes nas bases de dados PubMed, Science Direct, Scielo e Lilacs, a partir dos Descritores em Ciências da Saúde "DENTISTRY, CROSS INFECTION, COVID-19", inseridos na plataforma de maneira cruzada adotando a expressão booleana $A N D$. Dos 40 artigos identificados e selecionados para análise, 34 foram excluídos por apresentarem um ou mais critérios de exclusão. Portanto, seis artigos foram qualificados para inclusão nesta revisão. Resultados: Todos os trabalhos consultados apontam que apesar do alto risco de contaminação devido à proximidade com o paciente durante o atendimento e formação de aerossóis, a utilização de equipamentos de proteção individual e seguir normas de segurança tendem a reduzir drasticamente o índice de contaminação. Considerações finais: A pandemia do COVID-19 tem causado efeitos negativos em todo o mundo. Cabe a cada indivíduo seguir e respeitar as orientações de saúde para uma melhora dessa condição.

Palavras-chave: Dentista, Infecção cruzada, COVID-19.

\section{ABSTRACT}

Objective: To carry out a survey in the literature of the most recent information about the risk of cross-infection during dental care, as well as address care to prevent contamination by COVID-19. Methods: Systematized Literature Review. A complete search for recent studies was carried out in the PubMed, Science Direct, Scielo and Lilacs databases, based on Health Sciences Descriptors "DENTISTRY, CROSS INFECTION, COVID-19", inserted in the platform in a cross way using the Boolean expression AND. Of the 40 articles identified and selected for analysis, 34 were excluded for presenting one or more exclusion criteria. Therefore, six articles were qualified for inclusion in this review. Results: All the consulted works point out that despite the high risk of contamination due to proximity to the patient during the care and formation of aerosols, the use of personal protective equipment and following safety rules tend to drastically reduce the contamination index. Final considerations: The COVID-19 pandemic has caused negative effects worldwide, it is up to each individual to follow and respect the health guidelines for an improvement in this condition.

Key words: Dentistry, Cross infection, COVID-19.

\section{RESUMEN}

Objetivo: Realizar una encuesta en la literatura de la información más reciente sobre el riesgo de infección cruzada durante el cuidado dental, así como abordar la atención para prevenir la contaminación por COVID19. Métodos: Revisión sistemática de la literatura. Se realizó una búsqueda completa de estudios recientes en las bases de datos PubMed, Science Direct, Scielo y Lilacs, basadas en Descriptores de Ciencias de la Salud " DENTISTRY, CROSS INFECTION, COVID-19", insertadas en la plataforma de forma transversal utilizando la expresión booleana. De los 40 artículos identificados y seleccionados para el análisis, 34 se

\footnotetext{
${ }^{1}$ Universidade Federal de Sergipe (UFS), Aracaju - SE. *E-mail: luks_anjos@hotmail.com

2 Universidade Tiradentes (UNIT), Aracaju - SE.
}

SUBMETIDO EM: 6/2020

ACEITO EM: 7/2020

PUBLICADO EM: 9/2020 
excluyeron por presentar uno o más criterios de exclusión. Por lo tanto, seis los artículos fueron calificados para su inclusión en esta revisión. Resultados: Todos los trabajos consultados señalan que, a pesar del alto riesgo de contaminación debido a la proximidad al paciente durante el cuidado y la formación de aerosoles, el uso de equipos de protección personal y las siguientes reglas de seguridad tienden a reducir drásticamente el índice de contaminación. Consideraciones finales: La pandemia de COVID-19 ha causado efectos negativos en todo el mundo, depende de cada individuo seguir y respetar las pautas de salud para una mejora en esta condición.

Palabras clave: Dentista, Infección cruzada, COVID-19.

\section{INTRODUÇÃO}

A doença causada pelo novo coronavírus é uma infecção viral recém-descoberta que começou em Wuhan, na China, e causou surto de pneumonia no resto do mundo (KHADER Y, et al., 2020). Em 11 de março de 2020, a Organização Mundial da Saúde (OMS) anunciou que o surto mais recente da Síndrome Respiratória Aguda Grave (SARS-CoV-2), é uma pandemia atualmente conhecida como doença do Coronavírus 2019 (COVID-19) (FINI MB, 2020; OMS, 2020).

O coronavírus pertence à família de Coronaviridae, da ordem Nidovirales, compreendendo RNA grande, único e de cadeia positiva como seu genoma. Atualmente, existem quatro gêneros de coronavírus: $\alpha-C o V, \beta-$ $\mathrm{CoV}, \mathrm{Y}-\mathrm{CoV}, \delta$-CoV. A maioria dos coronavírus podem causar doenças infecciosas em humanos e vertebrados. O $\alpha$-CoV e $\beta$-CoV infecta principalmente o sistema nervosa, respiratório, gastrointestinal e central de humanos e mamíferos, enquanto $\mathrm{Y}$-CoV e $\delta$-CoV infectam principalmente as aves. O SARS-CoV-2 pertence ao $\beta$-CoV (NAKAGAWA K, et al., 2016; FAN Y, et al., 2019).

O período de incubação assintomática do vírus é estimado entre 2 e 14 dias. No entanto, foi relatado um período de incubação de até 24 dias em alguns estudos (ALHARBI A et al., 2020; LAI CC, et al., 2020). Os principais sintomas clínicos do COVID-19 são: tosse seca, febre alta, falta de ar, dor muscular, dor de garganta, confusão mental, dor no peito, dor de cabeça, rinorréia, alteração ou perda do olfato e paladar, insuficiência renal, diarreia, náusea e vômito (GUAN W, et al., 2020).

O SARS-CoV-2 pode ser transmitido de humano para humano por transmissão direta como tosse, espirro e inalação de gotículas, ou transmissão de contato como contato ocular, saliva e membranas mucosas do nariz (FINI MB, 2020). Mais de $80 \%$ dos casos são leves e se recuperam da doença sem a necessidade de tratamento especial. No entanto, cerca de $15 \%$ dos casos são categorizados como gravemente doentes e os $5 \%$ restantes como gravemente enfermos. Em casos graves e críticos, a doença respiratória aguda pode levar à pneumonia, insuficiência renal e até à morte (FINI MB, 2020).

Pacientes portadores de doenças crônocas como diabetes, obesidade, hipertensão, doenças pulmonares obstrutivas, doenças cardiovasculares e pessoas com mais de 60 anos de idade são enquadradas no grupo de risco por estarem mais susceptíveis a desenvolverem sintomas graves da COVID-19 (SILVA AM, et al., 2020).

Embora ainda seja cedo para determinar a taxa de mortalidade de casos, hoje, estima-se que seja superior a 4,5\% (OMS, 2020). Ainda que os casos leves de COVID-19 não exijam cuidados específicos, geralmente o tratamento sintomático e o isolamento domiciliar são suficientes. A oxigenoterapia é a principal intervenção para pacientes com casos graves.

O gerenciamento de casos críticos, por outro lado, depende do caso e geralmente precisará de cuidados intensivos (CHUGHTAI A e MALIK A, 2020; GUAN W, et al., 2020; OMS, 2020). As rotas de transmissão aumentam a preocupação com via de contágio por meio de saliva e aerossóis para o COVID-19 no ambiente odontológico caracterizando um quadro de infecção cruzada. (IBRAHIM NK, et al., 2017).

As condições de trabalho em que estão imersos os cirurgiões-dentistas, assim como os auxiliares e técnicos de saúde bucal, fazem com que estes profissionais estejam susceptíveis ao risco de contaminação cruzada que compreende a transmissão de patógenos, sejam eles vírus ou bactérias, entre pacienteprofissional e vice-versa, dentro do ambiente odontológico (GARCIA LP e BLANK VLG, 2006). 
Com o surgimento do Vírus da Imunodeficiência Humana (HIV), na década de 1980, que apresenta como principal forma de transmissão a contaminação por sangue, tornou-se essencial a utilização de equipamentos de proteção individual (EPIs) tanto para o cirurgião-dentista como para seu auxiliar, tal como medidas de desinfeção e esterilização dos equipamentos e instrumentais usados na prática odontológica (MINISTÉRIO DA SAÚDE, 2006).

Em seu estudo, Mooddey R, et al. (2018) mostraram que que a contaminação cruzada está entre o quarto problema ocupacional que mais acomete dentistas em sua prática diária, perdendo somente para problemas musculares causados por falta de ergonomia, estresse e lesões por perfurocortantes. Os autores ainda trazem que a utilização correta de EPIs e a vacinação em dia, são os principais e mais eficazes meios para barrar as infecções cruzadas que desencadeariam doenças como tuberculose, Hepatite B e C, e HIV. A saliva humana abriga inúmeras bactérias e vírus, e mais recentemente foi descoberto que o vírus SARS-CoV2 é encontrado em grande quantidade na cavidade oral em pacientes portadores da doença COVID-19, sendo a saliva sua principal forma de contágio (KHERSHID Z, et al., 2020).

A realização de procedimentos odontológicos demanda constante manipulação de fluidos salivares, e a utilização de motores de alto rotação geram aerossóis potencialmente contaminantes quando se atende pessoas portadores da COVID-19, mostrando-se um dos principais problemas no que se refere à contaminação cruzada nos dias atuais (ZI-YO GE, et al., 2020).

Tendo em vista o risco de contágio pelo novo coronavírus, um minucioso protocolo deve ser seguido para evitar a disseminação viral, como utilização de equipamentos de proteção individual, que compreendem luvas, máscara cirúrgica, viseira, touca, óculos de proteção, jaleco impermeável; enxaguantes bucais a base de peróxido de hidrogênio a $1 \%$ ou iodopovidona $0,2 \%$; isolamento absoluto com dique de borracha; peça de mão antirretração; desinfetantes apropriados como hipoclorito de sódio 1000 ppm ou $0,1 \%$ para superfícies e 10.000 ppm ou $1 \%$ para derramamentos de sangue; e descarte apropriado de resíduos gerados durante 0 atendimento (FALLAHI HD, et al., 2020).

Tendo em vista a gravidade e facilidade de transmissão do novo coronavírus, assim como sua virulência e risco a vida, em casos considerados graves, a Associação de Medicina Intensiva Brasileira (AMIB) sugere dividir o atendimento odontológico em três momentos para melhor controle e diminuição dos ricos de contaminação cruzada, sendo eles: cuidados antes do atendimento, durante o atendimento e após o atendimento. Diante disso, o presente estudo tem por finalidade realizar uma revisão sistematizada da literatura abordando os cuidados necessários que devem ser tomados pela equipe odontológica para evitar a contaminação cruzada do vírus SARS-CoV2 no período de pandemia.

\section{MÉTODOS}

Realizou-se uma revisão sistematizada da literatura, de cunho descritivo, por meio de pesquisa bibliográfica exploratória, nas bases de dados PubMed, Scielo, Lilacs, Science Direct. A pesquisa foi realizada no mês de maio de 2020, com o uso de descritores "DENTISTRY, CROSS INFECTION, COVID-19", que foram inseridos na plataforma de maneira cruzada adotando a expressão booleana " $A N D$ " (inserção de duas ou mais palavras). Após a seleção dos artigos, de acordo com os critérios de inclusão e exclusão descritos no Quadro 1, eles foram fichados e tabulados.

Quadro 1 - Critérios de inclusão e exclusão elencados para seleção dos artigos.

\begin{tabular}{|c|c|c|c|}
\hline $\begin{array}{c}\text { Critérios de } \\
\text { inclusão }\end{array}$ & $\begin{array}{c}\text { Estudos científicos em revistas nacionais ou } \\
\text { internacionais, que abrangem os descritores } \\
\text { propostos. }\end{array}$ & $\begin{array}{c}\text { Período: maio de } 2015 \text { a } \\
\text { maio de 2020. }\end{array}$ & Idiomas: Inglês. \\
\hline $\begin{array}{c}\text { Critérios de } \\
\text { exclusão }\end{array}$ & $\begin{array}{c}\text { Estudos científicos que não tratam do } \\
\text { objetivo proposto. }\end{array}$ & Texto: não disponível. & Outros Idiomas. \\
\hline
\end{tabular}

Fonte: Anjos LM, et al., 2020.

\section{RESULTADOS E DISCUSSÃO}

A combinação dos descritores na base de dados PUBMED, SCIELO, LILACS e SCIENCE DIRECT resultou em 40 estudos. Destes, 34 não preenchiam os critérios de inclusão estabelecidos previamente, restando seis artigos para revisão e leitura completa, como observamos na Figura 1. Os artigos selecionados para realização desse estudo estão descritos no Quadro 2. 
Figura 1 - Esquema da seleção dos artigos:

\section{DESCRITORES:}

dentistry and cross infection and COVID-19

PUBMED

Encontrados: 17

Excluídos: 13

Selecionados: 04

\section{SCIELO}

Encontrados: 04

Excluídos: 04

Selecionados: 00

\section{LILACS}

Encontrados: $\mathbf{0 0}$

Excluídos: 00

Selecionados: 00
SCIENCE DIRECT

Encontrados: 19

Excluídos: 17

Selecionados: 02

Fonte: Anjos LM, et al., 2020.

Quadro 2 - Resultado dos estudos selecionados.

\begin{tabular}{|c|c|c|c|c|}
\hline ID & Autoria/Ano & Periódico & $\begin{array}{c}\text { Tipo de } \\
\text { Estudo/Local }\end{array}$ & Resultados \\
\hline 1 & $\begin{array}{l}\text { ALHARBI A, et } \\
\text { al., } 2020\end{array}$ & $\begin{array}{l}\text { Saudi Dental } \\
\text { Society }\end{array}$ & $\begin{array}{l}\text { Revisão/Arábia } \\
\text { Saudita }\end{array}$ & $\begin{array}{l}\text { Para diminuir os riscos de infecções cruzadas no } \\
\text { consultório dentário, um protocolo seguro de atendimento } \\
\text { deve ser rigorosamente seguido. }\end{array}$ \\
\hline 2 & $\begin{array}{l}\text { CHAVES M, et } \\
\text { al., } 2020\end{array}$ & Braz. Oral Res & Revisão/Brasil & $\begin{array}{l}\text { Os procedimentos de controle de infecção cruzada para o } \\
\text { atendimento clínico de pacientes imunocomprometidos } \\
\text { devem seguir as mesmas diretrizes propostas para os } \\
\text { imunocompetentes. }\end{array}$ \\
\hline 3 & $\begin{array}{l}\text { FALLAHI HR, } \\
\text { et al., } 2020\end{array}$ & $\begin{array}{l}\text { Rev. Cirurgia } \\
\text { Maxillofacial } \\
\text { Plastic and } \\
\text { Reconstructive } \\
\text { Surgery } \\
\end{array}$ & $\begin{array}{l}\text { Revisão de } \\
\text { Literatura/Irã }\end{array}$ & $\begin{array}{l}\text { O dentista durante a prática odontológica está exposto a } \\
\text { diversos fluídos que podem transmitir o COVID-19, } \\
\text { levando a um quadro de infecção cruzada. Um adequado } \\
\text { protocolo deve ser seguido afim de diminuir os riscos } \\
\text { desse tipo de ocorrência. }\end{array}$ \\
\hline 4 & $\begin{array}{c}\text { GIUDICE R, } \\
2020\end{array}$ & $\begin{array}{l}\text { Int. J. Environ. } \\
\text { Res. Public } \\
\text { Health }\end{array}$ & Revisão/Itália & $\begin{array}{l}\text { Considerando a rota de transmissão do vírus, um } \\
\text { protocolo específico deve ser aplicado para reduzir o risco } \\
\text { de infecção cruzada. Este protocolo deve ser } \\
\text { implementado modificando o gerenciamento de pacientes } \\
\text { e a prática clínica, introduzindo dispositivos e práticas } \\
\text { organizacionais específicas. }\end{array}$ \\
\hline 5 & $\begin{array}{l}\text { NKENKE E e } \\
\text { ZIMMERMENN } \\
\quad \text { M, } 2020\end{array}$ & $\begin{array}{l}\text { Journal of } \\
\text { Cranio- } \\
\text { Maxillo-Facial } \\
\text { Surgery }\end{array}$ & Revisão/Áustria & $\begin{array}{l}\text { Para enfrentar adequadamente o desafio do COVID-19 } \\
\text { são necessárias mudanças significativas na infraestrutura } \\
\text { de unidades ambulatoriais, unidades de internação e } \\
\text { salas cirúrgicas, com o intuito de diminuir os riscos de } \\
\text { contaminação da equipe odontológica hospitalar e dos } \\
\text { pacientes. }\end{array}$ \\
\hline 6 & $\begin{array}{l}\text { ZI-YU GE, et } \\
\text { al., } 2020\end{array}$ & $\begin{array}{l}\text { Journal of } \\
\text { Zhejiang } \\
\text { University }\end{array}$ & Revisão/China & $\begin{array}{l}\text { Compreender como funciona a transmissão do novo } \\
\text { coronavírus por aerossol e suas implicações na } \\
\text { odontologia pode facilitar a identificação e correção de } \\
\text { negligência na prática odontológica diária, evitando casos } \\
\text { de infecção cruzada. Além das precauções padrão, } \\
\text { algumas precauções especiais que devem ser } \\
\text { implementadas durante um surto. }\end{array}$ \\
\hline
\end{tabular}

Fonte: Anjos LM, et al.,2020.

\section{Covid-19 e Odontologia}

A disseminação do novo coronavírus trouxe desafios significativos para toda a população e um grande impacto para várias profissões nos países afetados. A chegada do COVID-19 aos continentes não foi inesperada, tendo se originado no continente Asiático, na cidade de Wuhan (China) no final de 2019, percorreu o continente Europeu, América do Norte e América do Sul, respectivamente, sendo esses os mais afetados. A velocidade da reação e o tipo de resposta à pandemia dada pelas autoridades governamentais de cada país têm sido muito variáveis, tendo em vista os diferentes sistemas de saúde, economias e ideologias políticas (COULTHARD P, 2020).

Lai CC, et al. (2020) relatam que o período de incubação assintomática do vírus é de até 24 dias. No entanto, Alharbi A, et al. (2020) mostraram que devido à virulência do COVID-19 e ao fato de que alguns vírus podem estar presentes na saliva por até 29 dias após a recuperação do paciente, não se tem um tempo máximo exato de incubação, o que culmina em risco no aumento dos casos. 
De acordo com os conhecimentos sobre sinais e sintomas clínicos acerca das comorbidades causadas pela infecção do novo coronavírus, os profissionais de odontologia devem ser capazes de identificar um caso suspeito de COVID-19 para realizar a tomada de decisão sobre o atendimento imediato ou adiamento do mesmo. Em geral, um paciente gripal diagnosticado com SARS-CoV-2, ou com suspeita, deve evitar a visita a clínica odontológica, e o cirurgião-dentista precisa informá-lo da importância de permanecer em quarentena e procurar auxílio médico em caso de agravamento dos sintomas (YOUSEF KRSCD, et al., 2020).

Khader $Y$, et al. (2020), em sua pesquisa, questionaram 368 cirurgiões-dentistas sobre o risco/gravidade do vírus SARS-CoV-2 e obtiveram o seguinte resultado: um total de 65 (17,7\%) dos 368 dentistas consideraram o COVID-19 muito perigoso, $264(71,7 \%)$ moderadamente perigoso e $35(9,5 \%)$ o consideraram não perigoso. O que remete que muitos profissionais não estão cientes dos riscos envolvidos durante uma intervenção clínica, principalmente aqueles voltados para as formas de transmissão que são altamente predominantes durante $\mathrm{o}$ atendimento odontológico.

Segundo a American Dental Association (ADA), os procedimentos a serem realizados pelo cirurgiãodentista durante a pandemia são aqueles considerados emergências odontológicas que são definidos em situações que apresentam risco de morte ao indivíduo, como sangramento intenso, traumatismo envolvendo os ossos da face, comprometimento das vias aéreas; e urgências odontológicas, compreendendo condições que priorizam atendimento odontológico e que causam comorbidades, como casos de pulpite, cárie extensa ou restaurações que levam a sintomatologia dolorosa, pericoronarite, alveolite, abscessos, fratura dentoalveolar, cimentação de coroas, dentre outros (ADA, 2020).

Além de fornecer tratamento de caráter de urgência ou emergência, os cirurgiões-dentistas devem prestar atenção aos pacientes em relação a saúde psicológica durante o surto do novo coronavírus, pois, emergências de saúde pública podem afetar negativamente a saúde mental dos indivíduos (QU X e ZHOU X, 2020).

Em seu estudo, Jingjing YU, et al. (2020) relataram que um paciente que apresentou um diagnóstico de pulpite reversível causada por hipersensibilidade dentária teve um escore 8 em uma escala que registra nível da dor de $0-10$, sendo esse um número considerado muito alto, demonstrando extrema ansiedade e medo por relacionar o tratamento odontológico a possíveis comorbidades causadas pelo COVID-19. Durante o período de pandemia, os pacientes podem sofrer de estresse psicológico, portanto, os profissionais não devem se concentrar apenas nos tratamentos dentário, mas também em seu estado psicológico em momentos de emergência (ZI-YU GE, et al., 2020).

Segundo Alharbi A, et al. (2020), até o momento, não há protocolo ou diretriz universal estabelecido que seja inteiramente seguro para a prestação de atendimento odontológico a casos positivos ou suspeitos de COVID-19. Devido a isso, o atendimento odontológico parou completamente ou diminuiu significativamente em vários países afetados.

A contaminação cruzada nos consultórios odontológicos aumenta a sobrecarga dos departamentos de emergências médicas, podendo levar ao aumento da disseminação hospitalar do vírus SARS-CoV-2 para pacientes e/ou profissionais (HAMID RF, et al., 2020).

Porém, segundo a AMIB (2020) alguns cuidados já conhecidos foram aprimorados afim de auxiliar de forma prática e eficiente na redução do risco de infecção cruzada por parte dos profissionais em relação ao ambiente de atendimento odontológico, sendo esses cuidados divididos em protocolos para antes, durante 0 e após o atendimento como descritos no Quadro 4.

\section{Antes do atendimento}

Como forma de diminuir a ida dos pacientes ao consultório odontológico e assim, evitar possíveis aglomerações, principalmente, com pacientes diagnosticados com COVID-19, a tele-avaliação têm sido adotada.

Durante a avaliação que pode ser feita por meio de ligação telefônica ou vídeo conferência, o cirurgiãodentista deve fazer perguntas direcionadas ao novo coronavírus como: apresentou febre? apresentou problemas respiratórios: tosse, coriza dificuldade para respirar? viajou para localidades ou países com 
notificação ou transmissão do novo coronavírus? teve contato com pessoas com infecção confirmada? teve contato com pessoas que vieram de localidades que confirmaram a transmissão do novo coronavírus? teve contato com pessoas que confirmaram febre ou apresentou problemas respiratórios? participou de reuniões ou teve contato com muitas pessoas desconhecidas? (CRO-SE, 2020).

As perguntas feitas pelo cirurgião-dentista durante a tele-avaliação irão norteá-lo para os possíveis sintomas da COVID-19, e em caso positivo, deve encaminhá-lo para realização de teste e confirmação da doença, como também informar sobre a necessidade de isolamento social e procurar serviço de saúde somente em casos de agravamento dos sintomas (JINGJING YU, et al., 2020).

Após a identificação do seu estado de saúde geral, o profissional irá coletar informações sobre sua queixa principal e constatar se a mesma se trata de uma urgência ou emergência odontológica (ALHARB A, et al., 2020; CHAVES M, et al., 2020).

A Campanha de Vacinação contra a Influenza foi antecipada no Brasil como estratégia para diminuir a quantidade de pessoas com gripe neste inverno. A vacina não apresenta eficácia contra o novo coronavírus, porém é uma forma de auxiliar os profissionais de saúde a descartarem as influenzas na triagem e acelerarem o diagnóstico para o COVID-19 (AMIB, 2020).

Realizar higiene das mãos, preferencialmente com a lavagem rigorosa com água e sabão ou fricção com álcool em gel a 70\%, caso não estejam com sujidade visível, é imprescindível para remoção do vírus. As mãos devem ser lavadas antes e depois da retirada das luvas, e secadas com papel toalha (AMIB, 2020).

O auxiliar deve organizar o consultório a fim de deixar o mínimo de material exposto sobre as bancadas previamente ao atendimento, diminuindo, assim a contaminação de um a maior número de superfícies (HAINES A, et al., 2020).

\section{Durante $O$ atendimento}

A triagem presencial consiste na verificação dos sinais vitais, principalmente a aferição da temperatura corporal, onde um quadro de febre será definido para os pacientes que apresentarem temperatura acima de $37,8^{\circ} \mathrm{C}$ (AMIB, 2020).

As aglomerações devem ser evitadas na sala de espera, questionando os pacientes sobre a real necessidade de ir à consulta com acompanhantes e mantendo uma distância de pelo menos 1 metro entre as pessoas (GIUDICE R, 2020).

É importante o uso de bochecho com peróxido de hidrogênio a $1 \%$, iodopovidona a $0,2 \%$ ou cloreto de cetilpiridínio de $0,05 \%$ a $0,1 \%$, já que o SARS-CoV-2 é vulnerável à oxidação. O bochecho deve ser feito por um minuto antes do procedimento odontológico, para redução da quantidade de microrganismos na cavidade oral (IZZETTI R, et al., 2020).

Para a realização dos procedimentos, deve-se priorizar o uso da caneta de alta rotação sem spray de água ou a caneta de baixa rotação sem água, e sempre que possível optar pela utilização de instrumentos manuais (FALLAHI HR, et al., 2020).

Para reduzir a formação de aerossóis, a seringa tríplice e a cuspideira não devem ser utilizadas, sendo recomendado aspirar a cavidade oral constantemente como também utilizar isolamento absoluto, já que 0 mesmo veda o contato da cavidade com o ambiente.

Outra recomendação para reduzir a infecção entre paciente e dentista é optar por procedimentos menos invasivos, pois demandam de um menor e mais rápido contato com mucosa e secreção (ADA, 2020; HAINES A et al., 2020).

Tanto o cirurgião-dentista quanto a equipe devem utilizar os EPIs (como evidenciado no Quadro 3), além de receber treinamento de paramentação e desparamentação, remover adornos, remover a barba, não usar maquiagem e ausentar-se de suas atividades frente a sinais e sintomas de resfriado (NKENKE E ZIMMERMANN M, 2020). 
Quadro 3 - Equipamentos de Proteção Individual (EPI).

\begin{tabular}{|c|c|}
\hline Luvas & $\begin{array}{l}\text { Luvas de procedimentos não cirúrgicos devem ser utilizadas quando houver } \\
\text { contato das mãos do profissional com pessoas suspeitas ou confirmadas de } \\
\text { estarem contagiadas pelo novo coronavírus, principalmente se houver risco de } \\
\text { contato com sangue, fluidos corporais, secreções, mucosas e pele não íntegra, } \\
\text { bem como artigos ou equipamentos contaminados (AMIB, 2020; GIUDICE R, 2020; } \\
\text { NKENKE E e ZIMMERMENN M, 2020). }\end{array}$ \\
\hline Máscara cirúrgica & $\begin{array}{l}\text { Deve ser usada por toda equipe assistencial durante atendimento, devendo } \\
\text { possuir, no mínimo, uma camada interna, uma camada externa e, } \\
\text { obrigatoriamente, um elemento filtrante com eficiência de filtragem de partículas } \\
\text { (EFP) > 98\% e eficiência de filtragem bacteriológica (BFE) > 95\%, além do } \\
\text { certificado de aprovação junto ao INMETRO, sendo trocadas após cada paciente. } \\
\text { Em procedimentos nos quais serão gerados aerossóis, a máscara de escolha que } \\
\text { oferece melhor proteção é a N95 ou PFF2 ou respiradores reutilizáveis que } \\
\text { deverão ser limpos e desinfetados a cada paciente de acordo com recomendações } \\
\text { do fabricante, mas caso haja sujicidade na superfície e/ou umidade, devem ser } \\
\text { trocadas (AMIB, 2020; ZI-YU GE, et al., 2020). }\end{array}$ \\
\hline Capote ou avental & $\begin{array}{l}\text { Devem ser de punho de malha ou elástico com abertura posterior. Seu material } \\
\text { deve ser de tecido não tecido (TNT) com gramatura de no mínimo de } 30 \mathrm{~g} / \mathrm{m}^{2} \text { para } \\
\text { procedimentos simples e de } 50 \mathrm{~g} / \mathrm{m}^{2} \text { para os procedimentos que gerem aerossóis, } \\
\text { não alergênico e resistente, além de proporcionar barreira antimicrobiana efetiva } \\
\text { (Teste de Eficiência de Filtração Bacteriológica - BFE) e deve permanecer fechado } \\
\text { durante todos os procedimentos e ser removido a cada paciente (AMIB, 2020; } \\
\text { ANVISA 2020; NKENKE E e ZIMMERMENN M, 2020). }\end{array}$ \\
\hline $\begin{array}{l}\text { Protetores } \\
\text { oculares e faciais } \\
\text { (face shield) }\end{array}$ & $\begin{array}{l}\text { Diminuem o contato de gotículas com a face e a máscara, devem cobrir a frente e } \\
\text { as laterais do rosto e serem de uso exclusivo de cada profissional responsável pela } \\
\text { assistência. Após o uso, precisam ser limpos e desinfetados com álcool } 70 \% \text { ou } \\
\text { outro desinfetante padronizado pelo serviço de saúde para essa finalidade (AMIB, } \\
\text { 2020; FALLAHI HR, et al., 2020). }\end{array}$ \\
\hline $\begin{array}{l}\text { Gorro descartável } \\
\text { para cabeça e } \\
\text { capa de sapatos } \\
\text { descartáveis } \\
\text { (propé) }\end{array}$ & $\begin{array}{l}\text { Devem ser usados por toda equipe odontológica e pelos pacientes, sendo trocados } \\
\text { em caso de umidade e sujicidade. Além de calçados fechados e com solado } \\
\text { antiderrapante (AMIB, 2020). }\end{array}$ \\
\hline
\end{tabular}

Fonte: Anjos LM, et al., 2020.

Antes da paramentação o cirurgião-dentista deverá realizar a lavagem das mãos com água e sabão, ou a fricção com álcool $70 \%$, sendo essa uma prática constante no pré e pós-cirúrgico. O Conselho Federal de Odontologia (CFO) em parceria com a AMIB (2020) recomendam que seja seguida uma sequência correta para vestimenta dos EPIs, começando com a utilização do propré que deve ser usado assim que adentra o ambiente odontológico, seguida de nova higienização das mãos; colocação de capote ou avental, certificandose que o mesmo esteja corretamente posicionado cobrindo a maior área possível; posicionamento da máscara cirúrgica ou do tipo N95 ou PFF2, não devendo ser tocadas na região que estará em contato com rosto, mas sim em suas extremidades de apoio (elásticos); colocação de óculos de proteção seguido de gorro descartável, protetor facial e por fim as luvas de procedimento ou luvas do tipo cirúrgicas (AMIB, 2020; CFO, 2020).

\section{Após 0 atendimento}

A desinfecção dos óculos de proteção e protetor facial deve ser realizada a cada atendimento com água e sabão ou álcool $70 \%$ segundo recomendações do fabricante. Retirar-se da sala clínica para remoção da N95 afim não aspirar aerossóis gerados durante o atendimento, é de extrema importância para diminuir os riscos de contaminação cruzada (SUEN LKP, et al., 2020).

A desparamentação dos EPIs, tanto do cirurgião-dentista como do seu auxiliar, deve seguir um rigoroso protocolo já que os equipamentos de proteção individual utilizados estarão potencialmente contaminados após a realização do atendimento do paciente (SILVA AM, et al., 2020). A Anvisa (2020) recomenda remover os EPIs em nove passos, sendo eles respectivamente: tirar as luvas tomando o cuidado de não tocar a região contaminada com o resto do corpo; tirar o avental e despreza-lo imediatamente no lixo contaminado; lavar bem as mãos, tirar o gorro; tirar protetor facial (face shield); tira o óculos; lavar as mãos; tirar a máscara N95 
ou PFF2; e por fim lavar as mãos pela última vez. A desparamentação do auxiliar de saúde bucal deverá ser feita após a descontaminação do face shield usado pelo dentista, instrumentais e consultório (FRANCO JB, et al., 2020).

Após o atendimento odontológico a sala clínica deve ser fechada por uma a duas horas para a sedimentação das partículas de aerossóis do ar nas superfícies. Após este período realizar a limpeza terminal do consultório com $62-71 \%$ de etanol ou $0,1 \%$ de hipoclorito de sódio em 1 minuto ou quaternário de amônia $50 \%$ (HAINES A, et al., 2020).

O uso de barreiras como campos de TNT e papel filme colocados sobre a cadeira e mobiliário facilitam a limpeza do consultório, pois estes protegem os equipamentos dos aerossóis formados e devem somente ser retirados no momento da desinfecção do consultório. $O$ descarte de materiais contaminados como luvas e máscaras deve ser feito após cada atendimento e acondicionado em sacos plásticos fechados identificados como infectante. Os instrumentais e canetas de baixa e alta rotação devem ser esterilizados (SUEN LK, et al., 2020; ADA, 2020).

Quadro 4- Cuidados necessários no atendimento odontológico durante a pandemia do COVID-19.

\begin{tabular}{|c|c|c|}
\hline \multirow{3}{*}{$\begin{array}{l}\text { Antes do } \\
\text { atendimento }\end{array}$} & Medidas & Benefícios \\
\hline & Tele-avaliação & $\begin{array}{l}\text { Evita a ida de pacientes gripais ou confirmados } \\
\text { com COVID- } 19 \text { ao consultório, assim como } \\
\text { auxilia no diagnóstico da queixa principal, se a } \\
\text { mesma se trata de uma urgência ou } \\
\text { emergência odontológica. }\end{array}$ \\
\hline & $\begin{array}{l}\text { Mínimo de material exposto sobre as } \\
\text { bancadas previamente ao atendimento }\end{array}$ & $\begin{array}{l}\text { Diminui a contaminação de um maior número } \\
\text { de superfícies e objetos. }\end{array}$ \\
\hline \multirow{4}{*}{$\begin{array}{l}\text { Durante o } \\
\text { atendimento }\end{array}$} & Aferição da temperatura corporal & $\begin{array}{l}\text { Permite o profissional saber se o paciente } \\
\text { apresenta ou não sinais febris. }\end{array}$ \\
\hline & $\begin{array}{l}\text { Bochecho com peróxido de hidrogênio a } \\
1 \% \text {, iodopovidona a } 0,2 \% \text { ou cloreto de } \\
\text { cetilpiridínio de } 0,05 \% \text { a } 0,1 \%\end{array}$ & $\begin{array}{l}\text { Reduz a quantidade de microrganismos na } \\
\text { cavidade oral. }\end{array}$ \\
\hline & $\begin{array}{l}\text { Priorizar o uso da caneta de alta rotação } \\
\text { sem spray de água ou a caneta de baixa } \\
\text { rotação sem água, sempre que possível } \\
\text { optar pela utilização de instrumentos } \\
\text { manuais, aspirar a cavidade oral } \\
\text { constantemente (não usar a cuspideira) } \\
\text { como também utilizar isolamento absoluto }\end{array}$ & $\begin{array}{l}\text { Evita a formação de aerossóis, o que leva a } \\
\text { menor contaminação do dentista, auxiliar e do } \\
\text { consultório odontológico quando se atende } \\
\text { pacientes infectados pelo novo coronavírus. }\end{array}$ \\
\hline & $\begin{array}{l}\text { Utilização de todos os EPIs preconizados, } \\
\text { assim como seu correto uso, realizando a } \\
\text { correta paramentação, pelo cirurgião- } \\
\text { dentista e auxiliar de saúde bucal }\end{array}$ & $\begin{array}{l}\text { Evita a contaminação cruzada da equipe de } \\
\text { saúde bucal caso o paciente ou profissional } \\
\text { estejam com COVID-19. }\end{array}$ \\
\hline \multirow{7}{*}{$\begin{array}{l}\text { Após o } \\
\text { atendimento }\end{array}$} & $\begin{array}{l}\text { Retirar-se da sala clínica para remoção da } \\
\text { N95 }\end{array}$ & $\begin{array}{l}\text { Diminui os ricos de aspiração de aerossóis } \\
\text { gerados durante o atendimento, assim como } \\
\text { os riscos de contaminação cruzada. }\end{array}$ \\
\hline & $\begin{array}{l}\text { Desparamentação do cirurgião-dentista e } \\
\text { auxiliar seguindo correta sequência de } \\
\text { remoção dos EPls }\end{array}$ & $\begin{array}{l}\text { Reduz a propagação do SARS-CoV-2 entre os } \\
\text { profissionais evitando o contato das demais } \\
\text { partes do corpo, principalmente boca, nariz e } \\
\text { olhos, com os EPIs contaminados. }\end{array}$ \\
\hline & $\begin{array}{l}\text { Fechar a sala após atendimento por uma a } \\
\text { duas horas }\end{array}$ & $\begin{array}{l}\text { Permite a sedimentação das partículas de } \\
\text { aerossóis do ar nas superfícies. }\end{array}$ \\
\hline & $\begin{array}{l}\text { Limpeza terminal do consultório com } 62- \\
71 \% \text { de etanol ou } 0,1 \% \text { de hipoclorito de } \\
\text { sódio em } 1 \text { minuto ou quaternário de } \\
\text { amônia } 50 \%\end{array}$ & $\begin{array}{l}\text { Diminui de forma significativa a presença de } \\
\text { microrganismos do consultório. }\end{array}$ \\
\hline & $\begin{array}{l}\text { O uso de barreiras como campos de TNT e } \\
\text { papel filme colocados sobre a cadeira e } \\
\text { mobiliário. }\end{array}$ & $\begin{array}{l}\text { Facilitam a limpeza do consultório, pois estes } \\
\text { protegem os equipamentos dos aerossóis } \\
\text { formados durante o atendimento. }\end{array}$ \\
\hline & $\begin{array}{l}\text { Descarte de materiais contaminados como } \\
\text { luvas e máscaras deve ser feito após cada } \\
\text { atendimento e acondicionado em sacos } \\
\text { plásticos fechados identificados como } \\
\text { infectante }\end{array}$ & $\begin{array}{l}\text { Permite que os profissionais responsáveis pela } \\
\text { remoção dos resíduos do consultório realizem } \\
\text { o transporte dos mesmos de forma correta e } \\
\text { segura. }\end{array}$ \\
\hline & $\begin{array}{l}\text { Instrumentais e canetas de baixa e alta } \\
\text { rotação devem ser esterilizados }\end{array}$ & $\begin{array}{l}\text { Evita que ocorra contaminação cruzada do } \\
\text { vírus SARS-CoV-2 de um paciente para o } \\
\text { outro. }\end{array}$ \\
\hline
\end{tabular}

Fonte: Anjos LM, et al., 2020. 


\section{CONSIDERAÇÕES FINAIS}

Como relatado na literatura, a pandemia do SARS-CoV-2 tem mudado drasticamente o cenário mundial. Tendo o presente estudo o intuito de alertar e orientar os profissionais da odontologia e áreas afins sobre alto risco de contaminação durante 0 atendimento, preconizando o aprimoramento de seus hábitos diários na prevenção do contágio por meio da utilização de EPIs, no atendimento preferencial de urgências e emergências odontológicas, assim como seguir os cuidados determinados por entidades de saúde, contribuindo assim para minimizar a propagação do novo coronavírus. Além disso, existe a necessidade de estudos randomizados, controlados e duradouros para que haja uma padronização dos atendimentos clínicos a serem realizados e um maior conhecimento acerca desse recente vírus.

\section{REFERÊNCIAS}

1. AGÊNCIA NACIONAL DE VIGILÂNCIA SANITÁRIA. Nota técnica gvims/ggtes/Anvisa $\mathrm{n}^{\circ} 08 / 2020$ orientações para serviços de saúde: medidas de prevenção e controle que devem ser adotadas durante a assistência aos casos suspeitos ou confirmados de infecção pelo novo coronavírus (sars-cov-19). 2020.

2. ALHARBI A, et al. Diretrizes para prestação de cuidados odontológicos durante a pandemia de COVID-19. Saudi Dental Journal, 2020; 32: 181-186.

3. AMERICAN DENTAL ASSOCIATION. Covid-19 Resources for dentists. 2020.

4. AMIBE. Comitê de Odontologia AMIB de enfrentamento ao COVID-19 Departamento de Odontologia AMIB. 2020.

5. CHAVES M, et al. Immunocompromised patients and coronavirus disease 2019: a review and recommendations for dental health care. Oral Res, 2020; 34:e048.

6. CHUGHTAI A, MALIK A. É doença de Coronavírus (COVID-19) relação de fatalidade subestimada?. J. Glob. Biossegurança, 2020; 1 .

7. COULTHARD P. Dentistry and coronavirus (COVID-19)-moral decision-making. British Dental Journal, 2020; 228(7), 503505.

8. CFO. Recomendações AMIB/CFO para enfrentamento da COVID-19 na Odontologia. Conselho Federal de Odontologia (CFO), 2020.

9. CRO-SE. Manejo odontológico ambulatorial em tempos de covid-19. Decisão № 08/2020. Conselho Regional de Odontologia de Sergipe (CRO-SE), 2020.

10. FALLAHI HR, et al. Being a front-line dentist during the Covid-19 pandemic: a literature review. Maxillofacial Plastic and Reconstructive Surgery ,2020; 42:12.

11. FAN Y, et al. Coronavírus de bat na China. Vírus 11, 2019; 210.

12. FINI MB. What dentists need to know about COVID-19. Oral Oncology, 2020; 105 (2020) 104741.

13. FRANCO JB, et al. Cuidados Odontológicos na era do COVID19: recomendações para procedimentos odontológicos e profissionais. Rev. Assoc. Paul Cir. Dent, 2020.

14. GARCIA LP, BLANK VLG. Prevalência de exposições ocupacionais de cirurgiões-dentistas e auxiliares deconsultório dentário a material biológico. Cad. Saúde Pública, Rio de Janeiro, 2006; 22(1):97-108.

15. GIUDICE R. The Severe Acute Respiratory SyndromeCoronavirus-2 (SARS CoV-2) in Dentistry Management of Biological Risk in Dental Practice. Int. J. Environ. Res. Public Health, 2020; 17, 3067.

16. GUAN W, et al. Características clínicas da nova infecção por coronavírus em 2019 na China. 2020.

17. HAINES A., et al. Programme of community health workers for COVID-19 response. Lancet, 2020; (20).

18. IBRAHIM NK, et al. Infecção cruzada e controle de infecção em odontologia: conhecimento, atitude e prática de pacientes atendidos em clínicas dentárias no Hospital Universidade Abdulaziz King, Jeddah, Arábia Saudita. J Infectar Saúde Pública, 2017; 10 (4): 438-445.

19. IZZETTI R, et al. COVID-19 transmission in dental practice: brief review of preventive measures in Italy. Journal of dental research, 2020.

20. KHADER Y, et al. Dentists' Awareness, Perception, and Attitude Regarding COVID-19 and Infection Control: Cross-Sectional Study Among. Jordanian Dentists, 2020; 9;6(2).

21. KHURSHID Z, et al. Human Saliva: Non-Invasive Fluid for Detecting Novel Coronavirus (2019-nCoV). Int J Environ Res Public Health, 2020; 17(7): 2225.

22. LAI CC, et al. Síndrome respiratória aguda grave coronavírus 2 (SARS-CoV-2) e doença de coronavírus-2019 (COVID-19): a epidemia e os desafios. Int. J. Antimicrob. Agentes, 2020; 55.

23. MOODDEY R, et al. The prevalence of occupational health-related problems indentistry: A review of the literature. J Occup Health, 2018; 60: 111-125.

24. MINISTÉRIO DA SAÚDE. Controle de Infecções e da Patricia Odontológica em Tempos de AIDS. Manual de Conduta. Brasilia. Ministério da Saúde, 2006.

25. NAKAGAWA K. Avanços na pesquisa de vírus. Acadêmica Press, 2016; 96, $165-192$.

26. NKENK E, ZIMMERMENN M. Approaches to the management of patients in oral and maxillofacial surgery during COVID-19 pandemic. Journal of Cranio-Maxillo-Facial Surgery, 2020; 521 e526.

27. OMS. Situação de novo coronavírus da OMS (COVID-19). Cura Mundial. Órgão. 2020.

28. OMS. Relatório de Situação da Doença de Coronavírus 2019 - 41. Cura Mundial. Órgão. 2020.

29. QU X, ZHOU X. Intervenção psicológica em pacientes orais em um novo surto de pneumonia por coronavírus. Chin J Stomatol, 2020; 55.

30. SILVA AM, et al. Orientações aos cirurgiões dentistas para o atendimento odontológico a COVID-19. Departamento Odontologia da UFRGN. P. Abril, 2020.

31. SUEN LKP, et al. Comparing mask fit and usability of traditional and nanofibre N95 filtering facepiece respirators before and after nursing procederes. J Hosp Infect, 2020;104(3):336-343.

32. TURKISTANI KA. Precautions and recommendations for orthodontic settingsduring the COVID-19 outbreak: A review, American Journal of Orthodontics \& Dentofacial Orthopedics, 2020;04.016.

33. YOUSEF KRSCD, et al. Dentists' Awareness, Perception, and Attitude Regarding COVID-19 and Infection Control: CrossSectional Study Among Jordanian Dentists. JMIR Public Health Surveill, 2020; 6(2).

34. ZI-YU GE, et al. Possible aerosol transmission of COVID-19 andspecial precautions in dentistry. Journal of Zhejiang University-SCIENCE B (Biomedicine \& Bioechnology), 2020; 21(5): 361-368. 